TẠP CHÍ KHOA HỌC ĐẠI HỌC ĐÀ LẠT ～Tập 10, Số 1, 2020 129-141

\title{
THỎA THUẬn BẢO MẬT THÔNG TIN THEO QUY ĐỊNH CỦA BỘ LUẬT LAO ĐỘNG NĂM 2012
}

\author{
Nguyễn Văn Tố Hữu ${ }^{a^{*}}$ \\ ${ }^{a}$ Khoa Su phạm và Xã hội nhân văn, Truò̀ng Đại học Kiên Giang, Kiên Giang, Việt Nam \\ *Tác giả liên hệ: Email: nvthuu@vnkgu.edu.vn \\ Lịch sử bài báo \\ Nhận ngày 16 tháng 01 năm 2020 \\ Chỉnh sửa ngày 23 tháng 02 năm 2020 | Chấp nhận đăng ngày 09 tháng 3 năm 2020
}

\section{Tóm tắt}

Thỏa thuận bảo mật thông tin là một nội dung quan trọng và cũng là một thỏa thuận đặc biệt trong quan hệ lao động giữa nguời lao động và người sủ dụng lao động. Tuy nhiên, quy định pháp luật lao động Việt Nam hiện hành vẫn chua có huoơng dẫn chi tiết nhiều về nội dung này. Bài viết sẽ trình bày khái quát chung về thỏa thuận bảo mật thông tin, phân tích quy định pháp luật lao động Việt Nam hiện hành, chỉ ra nhũng điểm bất cập, và đề xuất một số kiến nghị nhằm hoàn thiện pháp luật về thỏa thuận bảo mật thông tin.

Từ khóa: Bảo mật thông tin; Lao động; Thỏa thuận.

DOI: http://dx.doi.org/10.37569/DalatUniversity.10.1.645(2020)

Loại bài báo: Bài báo nghiên cứu gốc có bình duyệt

Bản quyền @ 2020 (Các) Tác giả.

Cấp phép: Bài báo này được cấp phép theo CC BY-NC 4.0 


\title{
NON DISCLOSURE AGREEMENT UNDER LABOR CODE 2012
}

\section{Nguyen Van To Huu ${ }^{a^{*}}$}

${ }^{a}$ The Faculty of Pedagogy and Humanities Society, the Kiengiang University, Kiengiang, Vietnam

*Corresponding author: Email: nvthuu@vnkgu.edu.vn

\author{
Article history \\ Received: January $16^{\text {th }}, 2020$ \\ Received in revised form: February $23^{\text {rd }}, 2020 \mid$ Accepted: March $9^{\text {th }}, 2020$
}

\begin{abstract}
Non disclosure agreement is not only an important content but also a special agreement on the labor relation between employees and employers. However, the Vietnamese labor law does not guide to this problems. This paper to present, analyze current regulations' limitations as well as to provide solutions in particular about non disclosure agreement.
\end{abstract}

Keywords: Agreement; Labor; Non disclosue.

DOI: http://dx.doi.org/10.37569/DalatUniversity.10.1.645(2020)

Article type: (peer-reviewed) Full-length research article

Copyright $(92020$ The author(s).

Licensing: This article is licensed under a CC BY-NC 4.0 


\section{1. ĐặT VẤN ĐỀ}

Hợp đồng lao động (HĐLĐ) là hình thức pháp lý tạo căn cứ để các bên xác lập quan hệ lao động $(\mathrm{QHL})$ giữa người lao động $(\mathrm{NLĐ)}$ và người sử dụng lao động (NSDLĐ) một cách tự nguyện và bình đẳng nhằm bảo vệ quyền và lợi ích hợp pháp của các bên chủ thể trên cơ sở phù hợp với lợi ích chung của xã hội. HĐLĐ cũng là hình thức tuyển dụng lao động phù hợp, chủ yếu, và quan trọng để thiết lập QHLĐ trong nền kinh tế thị trường. Tại Điều 15 Bộ luật Lao động (BLLĐ) năm 2012 quy định: "Hợp đồng lao động là sự thỏa thuận giữa người lao động và người sử dụng lao động về việc làm có trả lương, điều kiện làm việc, quyền và nghĩa vụ của mỗi bên trong quan hệ lao động”. Có thể thấy, từ khái niệm HĐLĐ đã thể hiện đầy đủ các yếu tố của HĐLĐ: Hình thức của HĐLĐ có thể bằng văn bản hoặc lời nói; Bản chất của HĐLĐ là sự thỏa thuận giữa cá nhân NLĐ và NSDLĐ về các vấn đề thuộc QHLĐ; Chủ thể của HĐLĐ một bên là cá nhân NLĐ và một bên là NSDLĐ; Nội dung của HĐLĐ ghi nhận kết quả thỏa thuận về các vấn đề thuộc QHLĐ như: Việc làm có trả công, điều kiện lao động, quyền và nghĩa vụ của các bên... Để tạo điều kiện các bên thực hiện tốt nghĩa vụ của mình bên cạnh những thỏa thuận cơ bản mang tính nguyên tắc, thì nội dung HĐLĐ cũng có những thỏa thuận đặc biệt mang tính đơn phương và mang tính ràng buộc như: Thỏa thuận đào tạo và cam kết đào tạo; Thỏa thuận bảo mật thông tin... được xác lập trên cơ sở các bên tự do thỏa thuận và không trái quy định của pháp luật. Tuy nhiên, với vị trí thấp hơn của NLĐ cũng như một trong những đặc trưng của HĐLĐ là có sự phụ thuộc pháp lý của NLĐ với NSDLĐ nên NSDLĐ luôn luôn mong muốn thỏa thuận với NLĐ những thỏa thuận này nhằm mục đích đảm bảo lợi ích về sau cho mình. Hiện tại, pháp luật lao động Việt Nam hiện hành chỉ quy định một cách chung nhất, và chưa cụ thể về vấn đề bảo mật thông tin giữa các bên. Do đó, việc nghiên cứu nội dung "Thỏa thuận bảo mật thông tin trong Bộ luật lao động năm 2012" là rất cần thiết và góp phần nhằm hoàn thiện pháp luật lao động Việt Nam trong thời gian tới.

\section{KHÁI QUÁT VỀ THỎA THUẬN BẢO MẬT THÔNG TIN}

\subsection{Khái niệm về thỏa thuận bảo mật thông tin}

Theo BLLĐ năm 2012 tại Khoản 2 Điều 23:

Khi người lao động làm việc có liên quan trực tiếp đến bí mật kinh doanh, bí mật công nghệ theo quy định của pháp luật, thì người sử dụng lao động có quyền thỏa thuận bằng văn bản với người lao động về nội dung, thời hạn bảo vệ bí mật kinh doanh, bí mật công nghệ, quyền lợi và việc bồi thường trong trường hợp người lao động vi phạm.

Đây là điều khoản được xây dựng với mục đích ngăn ngừa, hạn chế sự cạnh tranh không lành mạnh giữa NLĐ đã thôi không làm việc và NSDLĐ, bảo vệ NSDLĐ, và bảo vệ quyền và lợi ích hợp pháp của NSDLĐ. Đây là một trong số những điều khoản hiếm hoi dành sự quan tâm và bảo vệ NSDLĐ trong khuôn khổ nguyên tắc bảo vệ quyền và lợi ích hợp pháp của NSDLĐ. Tuy nhiên, vì là điều khoản được cho phép đưa vào trong HĐLĐ theo quy định của BLLĐ năm 2012 nên cần thiết phải xem xét 
dưới các góc nhìn khác nhau để xây dựng cách giải thích phù hợp cho quy định của pháp luật, tạo điều kiện thuận lợi cho việc áp dụng quy định vào thực tiễn cũng như bảo vệ được quyền và lợi ích hợp pháp của các bên có liên quan (Đoàn, 2014, trang 67).

Do BLLĐ năm 2012 chỉ quy định duy nhất một điều khoản liên quan đến thỏa thuận bảo mật thông tin và cũng chỉ quy định một cách chung nhất là bí mật kinh doanh, bí mật công nghệ và cho phép các bên thỏa thuận về thời hạn bảo vệ, quyền lợi, và việc bồi thường khi NLĐ vi phạm chứ không có đưa ra khái niệm cụ thể về thỏa thuận bảo mật thông tin. Chính vì vậy, có thể hiểu khái niệm thỏa thuận bảo mật thông tin xuất phát từ quy định tại Khoản 2 Điều 23 BLLĐ năm 2012 như sau: "Thỏa thuận bảo mật thông tin là sự thỏa thuận giữa NSDLĐ và NLĐ về nội dung, phạm vi, thời hạn bảo vệ bí mật kinh doanh, bí mật công nghệ cho NSDLĐ”.

Từ đó, cần làm rõ như thế nào là bí mật kinh doanh và bí mật công nghệ. Đối với bí mật kinh doanh, theo Luật Sở hữu trí tuệ năm 2005 quy định tại khoản 23 Điều 4 như sau: "Bí mật kinh doanh là thông tin thu được từ hoạt động đầu tư tài chính, trí tuệ, chưa được bộc lộ và có khả năng sử dụng trong kinh doanh”. Để xác định những bí mật kinh doanh nào cần được thỏa thuận bảo mật thông tin thì pháp luật lao động không có đưa ra phạm vi giới hạn nào. Tuy nhiên có thể dựa vào quy định tại Điều 84 Luật Sở hữu trí tuệ năm 2005 thì các bí mật kinh doanh chỉ được bảo hộ khi đảm bảo điều kiện:

Không phải là hiểu biết thông thường và không dễ dàng có được; Khi được sử dụng trong kinh doanh sẽ tạo cho người nắm giữ bí mật kinh doanh lợi thế so với người không nắm giữ hoặc không sử dụng bí mật kinh doanh đó; Được chủ sở hữu bảo mật bằng các biện pháp cần thiết để bí mật kinh doanh đó không bị bộc lộ và không dễ dàng tiếp cận được.

Ngược lại, đối với bí mật công nghệ, mặc dù khái niệm bí mật công nghệ không được ghi nhận trong quy định của pháp luật nhưng cũng có thể hiểu rằng: Bí mật công nghệ là những công thức để tạo ra sản phẩm đặc trưng của doanh nghiệp đó.

Song song đó, tại Kỳ họp thứ 8 Quốc hội Khóa XIV ngày 20/11/2019 đã thông qua BLLĐ năm 2019 (có hiệu lực thi hành kể từ ngày 01/01/2021) sẽ thay thế BLLĐ năm 2012. Đây là một tiến bộ quan trọng do những sửa đổi trong BLLĐ sẽ cải thiện đáng kể vấn đề việc làm và $Q H L Đ$ của Việt Nam, tạo nền tảng vững chắc cho hội nhập quốc tế và thương mại công bằng (Văn phòng ILO Hà Nội, 2019). Tuy nhiên, BLLĐ năm 2019 vẫn giữ nguyên nội dung quy định về thỏa thuận bảo mật thông tin tại Khoản 2 Điều 21:

Khi người lao động làm việc có liên quan trực tiếp đến bí mật kinh doanh, bí mật công nghệ theo quy định của pháp luật thì người sử dụng lao động có quyền thỏa thuận bằng văn bản với người lao động về nội dung, thời hạn bảo vệ bí mật kinh doanh, bí mật công nghệ, quyền lợi và việc bồi thường trong trường hợp vi phạm.

Ta thấy, không có gì thay đổi so với BLLĐ năm 2012. Chính vì vậy, việc nghiên cứu về vấn đề thỏa thuận bảo mật thông tin là rất quan trọng và có ý nghĩa trên cơ sở BLLĐ năm 2012, thậm chí cho đển khi BLLĐ năm 2019 có hiệu lực áp dụng. 
Theo pháp luật lao động Việt Nam, việc quy định bảo mật thông tin cũng được xem là một nội dung khá quan trọng, vì vậy khi nghiên cứu về vấn đề này cần nắm rõ tinh thần và ý nghĩa của nó. Bởi lẽ, đây là điều khoản được các bên thỏa thuận bên cạnh những thỏa thuận trong HĐLĐ nhằm đảm bảo những quyền và lợi ích hợp pháp trong QHLĐ đối với những công việc có yêu cầu về bảo mật thông tin. Nội dung này được pháp luật Việt Nam nói riêng và các quốc gia khác nói chung quan tâm, ghi nhận, và đề cập nhằm hướng đến sự hoàn thiện hơn quy định về thỏa thuận bảo mật thông tin trong thực tế hiện nay. Ta thấy, khi tìm hiểu về quy định thỏa thuận bảo mật thông tin ở một số nước trên thế giới thì thuật ngữ dùng để mô tả vấn đề thỏa thuận bảo mật thông tin được thể hiện bằng thuật ngữ tiếng Anh là "Non disclosure agreement - NDA" hay được hiểu là điều khoản không cạnh tranh (Non compete clause-NCC) hoặc giao ước không cạnh tranh (Covenant not to compete-CNC).

Chẳng hạn như ở Liên bang Nga, từ khi Cách mạng tháng Mười thành công, Nga đã lần lượt ban hành bốn BLLĐ với nhiều lần được sửa đổi và bổ sung khác nhau. Tình trạng này xuất phát từ những thay đổi cơ bản chế độ kinh tế-xã hội của quốc gia này trong suốt gần một thế kỷ tồn tại và phát triển. BLLĐ đầu tiên ở Liên bang $\mathrm{Nga}$ được ban hành vào năm 1917 , bộ luật này chỉ quy định những vấn đề rất cơ bản về lao động như quyền và nghĩa vụ lao động, cấm bóc lột lao động, bảo hộ lao động, hạn chế thời giờ làm việc... BLLĐ năm 1917 áp dụng cho tất cả NLĐ làm công ăn lương và NSDLĐ ở mọi hình thức, kể cả cá nhân có thuê mướn lao động. Đầu những năm 1920, khi đã chuyển sang thời bình, nhu cầu sửa đổi BLLĐ năm 1917 được đặt ra để phù hợp với những điều kiện mới trong sản xuất và kinh doanh. Chính vì lý do đó, BLLĐ thứ hai ra đời vào năm 1922. Bộ luật này có ý nghĩa quan trọng trong việc điều chỉnh QHLĐ và tồn tại gần 10 năm cho đến khi BLLĐ thứ ba ra đời vào năm 1971, có hiệu lực từ ngày 01/01/1972. Đến năm 1992, BLLĐ năm 1971 lại sửa đổi rất cơ bản để phù hợp với việc chuyển đổi nền kinh tế từ cơ chế tập trung bao cấp sang cơ chế thị trường. Hiện tại, BLLĐ hiện hành của Liên bang Nga được ban hành vào năm 2001 và có hiệu lực từ ngày 01/01/2002. BLLĐ năm 2001 này là kết quả của quá trình pháp điển hóa pháp luật lao động ở Liên bang Nga. Nghiên cứu quy định BLLĐ ở Liên bang Nga liên quan đến vấn đề bảo mật thông tin được quy định và là một trong các trường hợp NSDLĐ chấm dứt HĐLĐ đối với NLĐ. Cụ thể tại Điều 81 cho rằng, $\mathrm{NSDLĐ} \mathrm{được} \mathrm{quyền} \mathrm{chấm} \mathrm{dứt}$ HĐLĐ với NLĐ khi tiết lộ những bí mật thông tin về tình trạng công việc, tổ chức, chính sách, kinh tế, và những thông tin khác liên quan đến công việc vì đó là trách nhiệm của NLĐ (Vladislav, 2002). Ta thấy quy định này cũng không khác gì so với pháp luật lao động Việt Nam, trong khi BLLĐ Việt Nam không quy định việc tiết lộ bí mật thông tin nằm trong các trường hợp chấm dứt HĐLĐ như BLLĐ ở Liên bang Nga mà ghi nhận tại Điều 126 BLLĐ năm 2012 quy định về áp dụng hình thức kỷ luật sa thải nếu NLĐ tiết lộ bí mật kinh doanh, bí mật công nghệ.

Ở Pháp, tại Điều L.152-7 của BLLĐ Pháp cấm nhân viên tiết lộ hoặc cố gắng tiết lộ bí mật thương mại thuộc về công ty của họ. Hơn nữa, Điều L.621-1 của Bộ luật Sở hữu trí tuệ Pháp quy định tội hình sự cho một giám đốc hoặc một nhân viên tiết lộ hoặc cố gắng tiết lộ cho các bên thứ ba bí mật thương mại. Các biện pháp trừng phạt là phạt tù tới hai năm và phạt tiền lên tới 30,000 Euro (Legifrance, 2002). Hay thậm chí ở Ấn Độ, theo Luật Hợp đồng của Ấn Độ năm 1872 tại Điều 27 đã điều chỉnh điều khoản 
bảo mật thông tin với mục đích là giữ kín bí quyết mà một công ty nắm giữ để có lợi thế cạnh tranh trên thị trường (India Code, 1872). Theo đó, pháp luật ở một số nước quy định cụ thể về chế tài khi vi phạm thỏa thuận bảo mật thông tin cũng như điều chỉnh nó tại một luật chuyên ngành một khi áp dụng trên thực tế sẽ trở nên dễ dàng, chặt chẽ hơn. Trong khi đó, ở Việt Nam lại không có luật chuyên ngành điều chỉnh cũng như không đưa ra chế tài xử lý cụ thể khi vi phạm mà chủ yếu phụ thuộc vào sự thỏa thuận của các bên trên cơ sở quy định của pháp luật hiện hành.

Nhìn chung, vấn đề thỏa thuận bảo mật thông tin đều được pháp luật ghi nhận ở mỗi nước, cũng như việc quy định về vấn đề này ở mỗi nước phụ thuộc vào ý chí chủ quan, điều kiện kinh tế-xã hội của mỗi quốc gia, ý thức chính trị của các nhà làm luật, mặt khác, ta thấy nó còn phù hợp với xu hướng chung của pháp luật quốc tế để bảo vệ các bên trong quá trình tham gia lao động. Chính điều này có ý nghĩa rất lớn trong quá trình nghiên cứu xây dựng hệ thống pháp luật lao động Việt Nam ngày càng hoàn thiện hơn, trong đó có quy định về thỏa thuận bảo mật thông tin để đảm bảo quyền và lợi ích của các bên trong QHLĐ ở Việt Nam.

\section{2. Đặc điểm của thỏa thuận bảo mật thông tin}

Thỏa thuận bảo mật thông tin là loại thỏa thuận đặc biệt, nó chỉ được thực hiện khi các bên có nhu cầu, đặc biệt là đối với NSDLĐ. Do đó, đặc điểm của thỏa thuận bảo mật thông tin khác hẵn so với những thỏa thuận khác như sau:

Một là, thỏa thuận bảo mật thông tin được ký kết cùng thời điểm với HĐLĐ, các bên có thể thỏa thuận là một điều khoản nằm trong HĐLĐ hoặc thành một thỏa thuận riêng biệt. Một khi NLĐ và NSDLĐ tham gia ký kết, xác lập HĐLĐ thì sẽ làm phát sinh QHLĐ giữa các bên. Do đó, đối với mỗi doanh nghiệp, NSDLĐ đều có những bí mật kinh doanh, bí mật công nghệ riêng cần phải được bảo mật. Nếu doanh nghiệp không thỏa thuận bảo mật thông tin thì dễ dẫn đến hậu quả bất lợi, có khả năng những thông tin này bị tiết lộ và ảnh hưởng đến lợi ích của chính doanh nghiệp mình. Chính lẽ đó, để bảo vệ quyền lợi của mình thì một khi NSDLĐ ký kết HĐLĐ với NLĐ thì cũng đồng thời ký kêt thỏa thuận bảo mật thông tin này. bao gồm:

Nội dung bắt buộc trong HĐLĐ quy định tại Khoản 1 Điều 23 BLLĐ năm 2012

Tên và địa chỉ người sử dụng lao động hoặc của người đại diện hợp pháp; Họ tên, ngày tháng năm sinh, giới tính, địa chỉ nơi cư trú, số chứng minh nhân dân hoặc giấy tờ hợp pháp khác của người lao động; Công việc và địa điểm làm việc; Thời hạn của hợp đồng lao động; Mức lương, hình thức trả lương, thời hạn trả lương, phụ cấp lương và các khoản bổ sung khác; Chế độ nâng bậc, nâng lương; Thời giờ làm việc, thời giờ nghỉ ngơi; Trang bị bảo hộ lao động cho người lao động; Bảo hiểm xã hội và bảo hiểm y tế; Đào tạo, bồi dưỡng, nâng cao trình độ kỹ năng nghề.

Theo đó, vấn đề thỏa thuận bảo mật thông tin không phải là nội dung bắt buộc phải có trong HĐLĐ, cho nên các bên có thể tự thỏa thuận nội dung này sao cho phù 
hợp với thực tế cũng như đảm bảo quyền và lợi ích hợp pháp của các bên trong QHLĐ, các bên có thể thỏa thuận một điều khoản bảo mật thông tin ngay trong chính HĐLĐ hay một phụ lục của HĐLĐ hoặc thỏa thuận riêng biệt với HĐLĐ.

Hai là, phạm vi của thỏa thuận chính là là bí mật kinh doanh và bí mật công nghệ. Phạm vi thỏa thuận bảo mật thông tin không gì khác chính là bí mật kinh doanh và bí mật công nghệ. Trong $\mathrm{QHLĐ,} \mathrm{NSDLĐ} \mathrm{với} \mathrm{tư} \mathrm{cách} \mathrm{là} \mathrm{chủ} \mathrm{sở} \mathrm{hữu} \mathrm{phải} \mathrm{có} \mathrm{quyền}$ quyết định việc tổ chức và điều hành sản xuất và kinh doanh để đạt hiệu quả cao nhất, đặc biệt là trong điều kiện kinh tế thị trường. NLĐ với tư cách là những người thực hiện công việc, để cùng hoàn thành kế hoạch sản xuất chung cần thiết phải có sự liên kết với nhau và phải đặt mình trong sự điều hành quản lý của NSDLĐ. Do đó, liên quan đến sự thành công, sự sống còn của mình thì NSDLĐ sẽ ký kết với NLĐ về thỏa thuận này một khi công việc của NLĐ có liên quan đến bí mật kinh doanh và bí mật công nghệ.

Ba là, tính hiệu lực về sau của thỏa thuận bảo mật thông tin khi HĐLĐ chấm dứt. Như đã biết, thỏa thuận bảo mật thông tin mặc dù được ký cùng lúc với HĐLĐ nhưng hiệu lực của thỏa thuận này có thể kéo dài hơn sau khi HĐLĐ đã chấm dứt. Sở dĩ, thông thường các bên ký kết thỏa thuận này trong một khoảng thời gian và không gian nhất định, có thể dài hơn hiệu lực của HĐLĐ để đảm bảo tính ràng buộc về sau khi NLĐ không còn làm việc cho NSDLĐ nữa. Trên thực tế, trường hợp HĐLĐ còn hiệu lực thì vấn đề thỏa thuận bảo mật thông tin đối với NLĐ thì không cần phải đặt nặng nhưng nếu một khi HĐLĐ kết thúc tức là QHLĐ giữa NLĐ và NSDLĐ chấm dứt, NLĐ không làm việc cho NSDLĐ này nữa mà chuyển sang làm việc cho NSDLĐ khác, lúc này nếu thỏa thuận bảo mật thông tin không còn hiệu lực thì có thể NLĐ sẽ tiết lộ những nội dung bí mật này và ngược lại nếu thời hạn thỏa thuận bảo mật thông tin này vẫn còn hiệu lực thì khi đó sẽ chuyển thành thỏa thuận trong pháp luật dân sự và được pháp luật dân sự điều chỉnh. Cho nên, tính hiệu lực về sau khi HĐLĐ chấm dứt là đặc điểm quan trọng và không thể thiếu khi giao kết của thỏa thuận bảo mật thông tin.

\section{QUY ĐỊNH PHÁP LUẬT VIỆT NAM HIỆN HÀNH VỀ THỎA THUẬN BẢO MậT THÔNG TIN}

\subsection{Hình thức thỏa thuận bảo mật thông tin}

Như đã biết, hình thức của hợp đồng là một trong những yếu tố pháp lý quan trọng có mối quan hệ biện chứng với các yếu tố khác của hợp đồng như bản chất, nội dung, giá trị hiệu lực, và thời điểm có hiệu lực của hợp đồng. Đây là phương tiện để diễn đạt ý chỉ của các bên ra bên ngoài cũng như để chứng minh sự tồn tại của hợp đồng.

Đối với HĐLĐ, giữa NSDLĐ và NLĐ có thể giao kết dưới hai hình thức là văn bản và lời nói. Cụ thể tại Điều 16 BLLĐ năm 2012:

1. HĐLĐ phải được giao kết bằng văn bản và được làm thành 02 bản, NLĐ giữ 01 bản, NSDLĐ giữ 01 bản, trừ trường hợp quy định tại Khoản 2 Điều này; 2 . Đối với công việc tạm thời có thời hạn dưới 03 tháng, các bên có thể giao kết HĐLĐ bằng lời nói. 
HĐLĐ bằng văn bản là một hình thức HĐLĐ, trong đó, các điều khoản thỏa thuận được ghi vào văn bản có chữ ký của các bên chủ thể. Ngược lại, HĐLĐ bằng lời nói do các bên thỏa thuận thông qua sự đàm phán, thương lượng bằng ngôn ngữ mà không lập thành văn bản, quá trình giao kết có thể có hoặc không có người làm chứng tùy theo yêu cầu của các bên (Lưu, 2014, tr. 242).

Đối với thỏa thuận bảo mật thông tin, về nguyên tắc, một khi NLĐ làm việc có liên quan đến bí mật kinh doanh và bí mật công nghệ thì giữa NSDLĐ và NLĐ có quyền thỏa thuận bằng văn bản về nội dung, thời hạn bảo vệ bí mật đó, quyền lợi và bồi thường trong trường hợp NLĐ vi phạm. Theo đó, pháp luật lao động Việt Nam hiện hành xác định rõ đây là quyền giữa các bên nếu các bên cảm thấy cần thiết phải ký kết thỏa thuận này và từ đó cũng quy định rõ hình thức thỏa thuận chính là văn bản. Do đặc thù của thỏa thuận bảo mật thông tin, nên pháp luật không quy định hình thức thỏa thuận bằng lời nói là điều tất yếu vì hình thức của thỏa thuận sẽ có vai trò quyết định giá trị pháp lý của nó và nhằm bảo vệ quyền lợi giữa các bên. Mặt khác, pháp luật lao động Việt Nam hiện hành cũng không bắt buộc các bên, một là có thể thỏa thuận thành một văn bản riêng hoặc có thể là một điều khoản nằm trong chính HĐLĐ thì hoàn toàn phụ thuộc vào nhu cầu của các bên nhằm đáp ứng yêu cầu công việc, phù hợp thực tế, và bảo đảm quyền lợi của các bên.

\subsection{Nội dung thỏa thuận bảo mật thông tin}

Nội dung của hợp đồng là toàn bộ các điều khoản quy định về quyền và nghĩa vụ của các bên tham gia vào QHLĐ. Như đã nghiên cứu ở phần trên, thỏa thuận bảo mật thông tin được hiểu là sự thỏa thuận giữa NSDLĐ và NLĐ về nội dung, phạm vi, thời hạn bảo vệ bí mật kinh doanh, và bí mật công nghệ cho NSDLĐ. Theo đó, trong nội dung của thỏa thuận có thể coi là các nội dung có ý nghĩa thực tế nhất đối với các bên chủ thể bởi trong đó bao gồm những ý chí và mong muốn của các bên, phản ánh đầy đủ quyền và lợi ích của các bên, khi ký kết các bên cần phải tuân thủ theo quy định của pháp luật. Tuy nhiên, do tính đặc trưng của thỏa thuận bảo mật thông tin và xuất phát từ nhu cầu của NSDLĐ nên thỏa thuận bảo mật thông tin bao giờ cũng mang ý chí chủ quan của họ mà về phía NLĐ không có sự lựa chọn nào khác.

Thứ nhất, nội dung thỏa thuận bảo mật thông tin trong thời gian NLĐ làm việc cho NSDLĐ. Đương nhiên NLĐ phải có nghĩa vụ bảo mật thông tin cho NSDLĐ theo quy định của pháp luật. Nội dung này áp dụng trong thời gian NLĐ làm việc cho NSDLĐ, bao gồm cả thời gian thử việc. Ngoài ra, mặc dù pháp luật không quy định cụ thể về nội dung thỏa thuận bảo mật thông tin nhưng NSDLĐ có thể thỏa thuận với NLĐ một số nội dung khác, cụ thể hơn sao cho phù hợp với quy định của pháp luật, không trái với đạo đức xã hội.

Thư hai, nội dung thỏa thuận bảo mật thông tin sau khi QHLĐ giữa NLĐ và NSDLĐ chấm dứt. Pháp luật lao động Việt Nam hiện hành không quy định rằng sau khi chấm dứt QHLĐ thì việc bảo mật thông tin như thế nào nhưng tại Khoản 2 Điều 23 BLLĐ năm 2012 quy định, trong đó có thỏa thuận về thời hạn bảo mật. Chính vì vậy, để đảm bảo quyền lợi của mình thì NSDLĐ thông thường sẽ thỏa thuận thời hạn bảo mật 
bao hàm cả trường hợp NLĐ chấm dứt HĐLĐ. Đây chính là bản chất đặc biệt của thỏa thuận bảo mật thông tin, khi HĐLĐ chấm dứt thì mặc nhiên không còn bất cứ ràng buộc về mặt pháp lý giữa NLĐ và NSDLĐ. Song song đó, NLĐ sau khi đã chấm dứt HĐLĐ với NSDLĐ, có thể NLĐ sẽ làm việc cho NSDLĐ mới thì khi đó việc thông tin mật của NSDLĐ cũ có thể mai một là điều không thể tránh khỏi và đặc biệt là đối với đối thủ cạnh tranh trên thị trường.

\subsection{Bồi thường thiệt hại khi vi phạm thỏa thuận bảo mật thông tin}

Trong mọi hệ thống pháp luật, khi có hành vi vi phạm hợp đồng (một bên chậm thực hiện nghĩa vụ, không thực hiện nghĩa vụ hoặc thực hiện nghĩa vụ không đúng cam kết) thì một trong những biện pháp có thể được áp dụng nhằm khắc phục hậu quả của hành vi vi phạm hợp đồng là bồi thường thiệt hại. Theo Bộ luật Dân sự (BLDS) 2015 tại Điều 360 quy định: "Trường hợp có thiệt hại do vi phạm nghĩa vụ gây ra thì bên có nghĩa vụ phải bồi thường toàn bộ thiệt hại, trừ trường hợp có thỏa thuận khác hoặc luật có quy định khác", theo quy định này đã ghi nhận khái quát trách nhiệm bồi thường thiệt hại do vi phạm nghĩa vụ bao gồm: Trách nhiệm bồi thường thiệt hại do vi phạm hợp đồng và trách nhiệm bồi thường thiệt hại ngoài hợp đồng, đồng thời, cũng chỉ rõ nguyên tắc của bồi thường thiệt hại và căn cứ làm phát sinh trách nhiệm bồi thường thiệt hại. Theo đó, bao gồm ba căn cứ: i) Có hành vi vi phạm nghĩa vụ; ii) Có thiệt hại; và iii) Có mối quan hệ nhân quả giữa hành vi vi phạm nghĩa vụ và thiệt hại xảy ra. Khác với pháp luật dân sự, Luật Thương mại (LTM) năm 2005 quy định tại Khoản 1 Điều 229: "Bồi thường thiệt hại là việc bên có quyền lợi bị vi phạm yêu cầu bên vi phạm trả tiền bồi thường thiệt hại do vi phạm hợp đồng gây ra". Chính vì lẽ đó, LTM tiếp cận bồi thường thiệt hại do vi phạm hợp đồng dưới góc độ là quyền yêu cầu của bên có quyền lợi bị vi phạm đối với bên vi phạm, theo đó bên vi phạm phải trả tiền bồi thường thiệt hại do vi phạm hợp đồng gây ra. Đối với pháp luật lao động, vấn đề bồi thường thiệt hại được quy định tại Khoản 1 Điều 130 BLLĐ năm 2012, "Người lao động làm hư hỏng dụng cụ, thiết bị hoặc có hành vi khác gây thiệt hại tài sản của người sử dụng lao động thì phải bồi thường theo quy định của pháp luật". Theo pháp luật lao động thì bồi thường thiệt hại có thể hiểu là việc một bên đền bù cho bên kia một giá trị nhất định do có hành vi vi phạm. Thông thường khi có hành vi vi phạm và thiệt hại xảy ra thì vấn đề bồi thường sẽ được đặt ra và bồi thường luôn gắn với thiệt hại.

Đối với trường hợp thỏa thuận bảo mật thông tin thì hoàn toàn không quy định cụ thể như quy định của BLDS, LTM hay thậm chí BLLĐ mà chỉ đặt ra trách nhiệm bồi thường khi NLĐ vi phạm thỏa thuận. Tại Khoản 2 Điều 23 BLLĐ năm 2012:

Khi người lao động làm việc có liên quan trực tiếp đến bí mật kinh doanh, bí mật công nghệ theo quy định của pháp luật, thì người sử dụng lao động có quyền thỏa thuận bằng văn bản với người lao động về nội dung, thời hạn bảo vệ bí mật kinh doanh, bí mật công nghệ, quyền lợi và việc bồi thường trong trường hợp người lao động vi phạm. 
Việc quy định trách nhiệm bồi thường này là hoàn toàn hợp lý vì để đảm bảo quyền lợi cho NSDLĐ thì NLĐ phải có trách nhiệm của mình một khi NLĐ làm những công việc liên quan trực tiếp đến bí mật kinh doanh và bí mật công nghệ của NSDLĐ.

\section{THỰC TRẠNG QUY ĐỊNH PHÁP LUẬT VỀ THỎA THUẬn BẢO MậT THÔNG TIN VẢ MỘT SỐ KIỂN NGH!̣}

Việc quy định vấn đề thỏa thuận bảo mật thông tin trong lao động có ý nghĩa rất quan trọng đối với các bên chủ thể khi tham gia vào QHLĐ mà đặc biệt đối với những công việc liên quan đến bí mật kinh doanh và bí mật công nghệ. Về phía NSDLĐ, việc quy định này là một công cụ và biện pháp giúp cho NSDLĐ tự bảo vệ chính mình, cũng như đối với NLĐ là góp phần nâng cao ý thức và phải có trách nhiệm đối với NSDLĐ khi làm việc trong môi trường có yếu tố bảo mật về kinh doanh và công nghệ. Tuy nhiên, do chỉ quy định duy nhất một điều khoản trong BLLĐ năm 2012 nên việc thỏa thuận bảo mật thông tin chắc chắn sẽ phát sinh một số bất cập nhất định. Cụ thể như sau:

- Một là, chưa giải thích cụ thể khái niệm về thỏa thuận bảo mật thông tin cũng như khái niệm bí mật kinh doanh và bí mật công nghệ theo quy định của pháp luật lao động dẫn đển việc áp dụng còn chưa triệt để trong thực tiễn. Hiện tại pháp luật lao động Việt Nam hiện hành quy định nghiêng về bảo vệ phía NSDLĐ nhiều hơn so với NLĐ. Chính vì lẽ đó, việc giải thích rõ sẽ giúp các bên nắm được tinh thần quy định của pháp luật mà sử dụng tích cực hơn và chủ động hơn. Đặc biệt là đối với NLĐ, phải nắm rõ trách nhiệm của mình trong việc bảo mật thông tin một khi làm việc trong môi trường có yếu tố bí mật về kinh doanh và công nghệ.

- Hai là, về phạm vi bảo mật thông tin đối với bí mật kinh doanh và bí mật công nghệ, pháp luật lao động không quy định cụ thể cũng như chưa giới hạn phạm vi của nó. Do đó, rất khó xác định được bí mật nào là bí mật kinh doanh và công nghệ để từ đó xác định được hành vi nào là hành vi vi phạm thỏa thuận. Điều này ảnh hưởng rất lớn đến NLĐ nếu không được thỏa thuận rõ ràng, một khi NSDLĐ- chủ thể quản lý NLĐ, chắc chắn sẽ áp dụng những quy định và quy chế riêng của mình để xác định hành vi xâm phạm thỏa thuận, lúc đó NLĐ sẽ gặp bất lợi hơn.

- Ba là, BLLĐ năm 2012 đã quy định rõ khi NLĐ làm việc có liên quan trực tiếp đến bí mật kinh doanh và bí mật công nghệ thì NSDLĐ có quyền thỏa thuận bằng văn với $\mathrm{NLĐ} \mathrm{về} \mathrm{nội} \mathrm{dung,} \mathrm{thời} \mathrm{hạn,} \mathrm{quyền} \mathrm{lợi,} \mathrm{và} \mathrm{việc} \mathrm{bồi} \mathrm{thường} \mathrm{khi} \mathrm{NLĐ}$ vi phạm. Theo đó, chỉ những NLĐ nào làm việc trực tiếp ảnh hưởng đến bí mật kinh doanh và bí mật công nghệ của NSDLĐ mà NSDLĐ yêu cầu cam kết thỏa thuận thì mới áp dụng Khoản 2 Điều 23 BLLĐ năm 2012 này. Ngược lại, điểm bất cập ở trên thì lại gây thiệt hại cho NSDLĐ bởi vì quy định chưa bao hàm hết đối tượng chủ thể cần phải ký cam kết thỏa thuận này, một NLĐ bình thường làm việc cho NSDLĐ hay thậm chí đối tượng là NLĐ khác có liên quan đến bí mật kinh doanh và bí mật công nghệ cũng ít nhiều nắm được những thông tin về 
NSDLĐ sẽ dễ xảy ra tình trạng rò rỉ thông tin ra bên ngoài mà không hẳn chỉ những NLĐ làm việc liên quan trực tiếp đến bí mật kinh doanh và công nghệ.

- Bốn là, vấn đề bồi thường thiệt hại khi vi phạm thỏa thuận bảo mật thông tin, từ quy định cho thấy, luật đang có hướng nghiên về bảo vệ NSDLĐ nhiều hơn và chỉ đặt ra trách nhiệm bồi thường chứ không phải là bồi thường thiệt hại. Do đó, NLĐ lại bị ràng buộc nghĩa vụ rất lớn khi thỏa thuận được xác lập và NLĐ một khi vô ý hay cố ý tiết lộ bí mật thông tin và bí mật công nghệ đã cam kết thì phải bồi thường cho dù không có thiệt hại xảy ra và quy định của luật cũng không xác định mức bồi thường như thế nào.

- Năm là, không quy định rõ thời hạn bảo mật, trong trường hợp QHLĐ chấm dứt thì thỏa thuận bảo mật thông tin giữa các bên sẽ như thế nào, thời hạn thỏa thuận với thời gian là bao lâu. Khác hẳn với trường hợp cán bộ và công chức làm việc có liên quan đến bí mật nhà nước. Theo đó tại Điều 19 Luật Cán bộ, Công chức năm 2008 quy định:

Cán bộ, công chức không được tiết lộ thông tin liên quan đến bí mật nhà nước dưới mọi hình thức; Cán bộ, công chức làm việc ở ngành, nghề có liên quan đến bí mật nhà nước thì trong thời hạn ít nhất là 05 năm, kể từ khi có quyết định nghỉ hưu, thôi việc, không được làm công việc có liên quan đến ngành, nghề mà trước đây mình đã đảm nhiệm cho tổ chức, cá nhân trong nước, tổ chức, cá nhân nước ngoài, hoặc liên doanh với nước ngoài.

Một khi cán bộ và công chức nghỉ hưu hoặc thôi việc thì không được làm công việc có liên quan đến ngành nghề mà mình đã làm trước đây trong thời hạn ít nhất năm năm để tránh trường hợp bí mật nhà nước bị xâm hại. Đối với NLĐ, một khi chấm dứt HĐLĐ với NSDLĐ mà công việc có liên quan đến bí mật kinh doanh và bí mật công nghệ thì không có quy định cụ thể và triệt để như pháp luật cán bộ và công chức. Do đó, các bên sẽ gặp khó khăn khi gặp trường hợp này thay vì "giới hạn do một điều khoản cấm cạnh tranh". Giới hạn này có nghĩa là doanh nghiệp - NSDLĐ có quyền đòi hỏi NLĐ của mình phải cam kết là sẽ không được làm cho một NSDLĐ khác sau khi đã chấm dứt HĐLĐ với mình. Do trong quá trình làm việc cho một NSDLĐ, NLĐ đã có được nhiều hiểu biết chuyên môn hay những bí mật sản xuất, kinh doanh, đối tác, khách hàng... của NSDLĐ. Một khi NLĐ đi làm việc cho NSDLĐ khác và có thể đem những hiểu biết này cho NSDLĐ mới, điều này sẽ gây bất lợi cho NSDLĐ ban đầu và giới hạn này cũng cho phép NSDLĐ yêu cầu NLĐ cam kết không thực hiện các công việc mà mình đã thực hiện với NSDLĐ ban đầu.

Để xây dựng được quy định về thỏa thuận bảo mật thông tin một cách chặt chẽ, khoa học, và đảm bảo quyền và lợi ích hợp pháp của các bên trong thỏa thuận, tác giả kiến nghị thực hiện những giải pháp cơ bản sau: Đầu tiên, nên quy định cụ thể khái niệm thỏa thuận bảo mật thông tin cũng như khái niệm bí mật kinh doanh và bí mật công nghệ theo quy định của pháp luật lao động, thay vì phải đối chiếu khái niệm với quy định của pháp luật khác có liên quan. Quy định cụ thể tại Điều 3 về giải thích từ ngữ hay thậm chí quy định một điều khoản riêng trong BLLĐ. Tiếp theo đó, nên ban 
hành các nghị định và thông tư hướng dẫn chi tiết cụ thể về một số nội dung liên quan đến thỏa thuận bảo mật thông tin như sau:

- Nên giới hạn phạm vi thỏa thuận bảo mật thông tin cũng như xác định thỏa thuận nào là bí mật kinh doanh và bí mật công nghệ để các bên tự do lựa chọn thỏa thuận, tránh trường hợp NSDLĐ luôn áp đặt những quyền lợi riêng cho mình mà NLĐ không được lựa chọn và việc giới hạn này làm cho việc xác định hành vi nào là hành vi vi phạm thỏa thuận về bảo vệ bí mật kinh doanh và bí mật công nghệ được dễ dàng hơn trong thực tiễn;

- Khoản 2 Điều 23 BLLĐ nên xác định lại đối tượng chủ thể phải có trách nhiệm bảo mật thông tin của NSDLĐ. Trong trường hợp này, nên quy định bao gồm những đối tượng dù không tham gia hoặc liên quan trực tiếp đến bí mật kinh doanh, bí mật công nghệ của NSDLĐ để bảo vệ quyền lợi của NSDLĐ;

- Mặc dù pháp luật lao động Việt Nam hiện hành quy định về thỏa thuận bảo mật thồng tin một cách hài hòa giữa quyền lợi và nghĩa vụ giữa các bên, NSDLĐ có quyền thỏa thuận để bảo vệ quyền lợi của mình cũng như một khi đã thỏa thuận thì về phía NLĐ cũng phải có những quyền lợi nhất định để đổi lại việc phải bảo vệ những bí mật của NSDLĐ và cả trách nhiệm phải bồi thường nếu vi phạm, nhưng BLLĐ năm 2012 chỉ quy định một cách chung chung, không rõ ràng. Cho nên, cần phải xác định rõ nội dung và quyền lợi hợp pháp của các bên khi tham gia ký kêt thỏa thuận, đặc biệt là quy định rõ thời hạn thỏa thuận nên ấn định một thời hạn tối đa cho việc bảo mật thông tin mà NLĐ cần phải thực hiện kể cả trường hợp QHLĐ chấm dứt cũng như một số trường hợp NLĐ không cần phải thực hiện nghĩa vụ bảo mật này sau khi QHLĐ chấm dứt như NSDLĐ đơn phương chấm dứt HĐLĐ với NLĐ trái pháp luật và NLĐ chọn giải pháp không quay trở lại làm việc cho NSDLĐ.

\section{KẾT LUẬn}

Tóm lại, thỏa thuận bảo mật thông tin trong lao động là một vấn đề pháp lí quan trọng và là một thỏa thuận đặc biệt mà các bên cần phải quan tâm khi tham gia vào QHLĐ. Tuy nhiên, do pháp luật lao động Việt Nam hiện hành chỉ quy định duy nhất tại Khoản 2 Điểu 23 BLLĐ năm 2012 nên cần phải được hướng dẫn chi tiết và cụ thể quy định này để có thể áp dụng vào thực tiễn cũng như cần phải hoàn thiện các quy định về thỏa thuận bảo mật thông tin nhằm đảm bảo hài hoà quyền và lợi ích hợp pháp của NLĐ và NSDLĐ.

\section{TÀI LIỆU THAM KHẢO}

Đoàn, T. P. (2014). Điều khoản bảo mật-hạn chế cạnh tranh trong hợp đồng lao động theo quy định của pháp luât lao động Việt Nam hiện hành. Bài viết được trình bày tại Hội thảo Một số vấn đề pháp lý liên quan đến hợp đồng lao động theo quy định của Bộ luật Lao động năm 2012, Việt Nam. 
India Code. (1872). The Indian contract act. Retrieved from https://indiacode.nic.in/ showdata?actid=AC_CEN_3_20_00035_187209_1523268996428\&sectionId=3 $8631 \&$ sectionno $=27 \&$ orderno $=28$.

Legifrance. (2002). Code du travail. Retrieved from https://www.legifrance.gouv.fr/ affichCodeArticle.do?idArticle=LEGIARTI000006646587\&cidTexte=LEGITE XT000006072050\&dateTexte $=20020101$.

Lưu, B. N. (2014). Giáo trình Luật Lao động Việt Nam. Hà Nội, Việt Nam: NXB. Công an nhân dân.

Quốc Hội. (2005). Luật Sở hũu trí tuệ. Hà Nội, Việt Nam: NXB. Chính trị quốc gia.

Quốc Hội. (2005). Luật Thuoong mại . Hà Nội, Việt Nam: NXB. Chính trị quốc gia.

Quốc Hội. (2008). Luật Cán bộ, công chức. Hà Nội, Việt Nam: NXB. Chính trị quốc gia.

Quốc Hội. (2012). Bộ luật Lao động năm 2012. Hà Nội, Việt Nam: NXB. Lao động.

Quốc Hội. (2016). Bộ luật Dân sự 2015. Hà Nội, Việt Nam: NXB. Chính trị quốc gia.

Quốc Hội. (2019). Bộ luật Lao động năm 2019. Được truy lục từ https://thuvienphap luat.vn/van-ban/Lao-dong-Tien-luong/Bo-Luat-lao-dong-2019-333670.aspx

Văn phòng ILO Hà Nội. (2019). Bộ luật Lao động sưa đổi giúp nguời lao động huơong lợi công bằng tù tăng truơong kinh tế. Được truy lục từ https://www.ilo.org/ hanoi/Informationresources/Publicinformation/newsitems/WCMS_729340/lang-vi/index.htm.

Vladislav, E. (2002). National labour law profile: Russian Federation. Retrieved from http://www.ilo.org/ifpdial/information-resources/national-labour-law-profiles/ WCMS_158917/lang--en/index.htm. 